\section{Stereotactic and Functional Neurosurgery}

Stereotact Funct Neurosurg 2010;88:315-321

DOI: $\underline{10.1159 / 000319959}$
Received: December 1, 2009

Accepted after revision: April 11, 2010

Published online: August 13, 2010

\title{
Stereotactic Radiosurgery for Spine Tumors: Review of Current Literature
}

\author{
Wesley Hsu Trang Nguyen Lawrence Kleinberg Eric C. Ford \\ Daniele Rigamonti Ziya L. Gokaslan Michael Lim \\ Department of Neurosurgery, Johns Hopkins Medical Institutions, Baltimore, Md., USA
}

\section{Key Words}

Spine tumor $\cdot$ Spinal cord tumor • Radiosurgery

Metastatic spine disease $\cdot$ Stereotaxy

\begin{abstract}
Stereotactic radiosurgery (SR) is increasingly utilized for the treatment of intracranial and extracranial pathology. It is considered an important adjuvant to surgery, chemotherapy or fractionated radiotherapy, and the role of SR as a primary treatment modality continues to be explored. Although SR for spinal lesions is in its infancy, there is a growing body of literature supporting its efficacy. The purpose of this review is to summarize the pertinent literature regarding the use of SR for lesions of the spine and spinal cord. Particular emphasis will be placed on large clinical series of both primary and secondary spine tumors.
\end{abstract}

Copyright $\odot 2010$ S. Karger AG, Basel

\section{Introduction}

Stereotactic radiosurgery (SR) is increasingly utilized for the treatment of intracranial and extracranial pathology. It is considered an important adjuvant to sur- gery, chemotherapy or fractionated radiotherapy, and the role of SR as a primary treatment modality continues to be explored. SR was recently defined as using 'externally generated ionizing radiation ... to inactivate or eradicate (a) defined target(s) in the head or spine ... performed in a limited number of sessions, up to a maximum of five' [1]. SR was first conceived by Lars Leksell [2] as a potential tissue ablation modality for intracranial functional neurosurgery. Collateral damage to adjacent structures was occasionally problematic with the early use of SR, but improved stereotactic imaging allowed for better target localization and delineation of adjacent structures [3]. The use of computer-aided tracking systems improved targeting of radiation while excluding normal tissue [4]. Collectively, these advances improved the accuracy and efficacy of SR for intracranial lesions while limiting treatment morbidity. SR is now well established as having a role in the treatment of intracranial disease $[5,6]$.

During the mid-1990s, investigators sought to expand the scope of SR to extracranial pathology, specifically tumors of the spine. In 1996, Hamilton et al. [7] first reported the use of SR for spinal pathology using a linear accelerator. Further improvements in frameless stereotactic technology also allowed for advanced targeting ca-

\section{KARGER}

Fax +41613061234 E-Mail karger@karger.ch www.karger.com
(C) 2010 S. Karger AG, Base

$1011-6125 / 10 / 0885-0315 \$ 26.00 / 0$

Accessible online at:

www.karger.com/sfn
Wesley Hsu, MD

Department of Neurosurgery

Johns Hopkins University School of Medicine, Meyer Bldg. 8-161

600 North Wolfe Street, Baltimore, MD 21287 (USA)

Tel. +1 410292 6713, Fax +1 410502 5768, E-Mail weshsu@jhmi.edu 


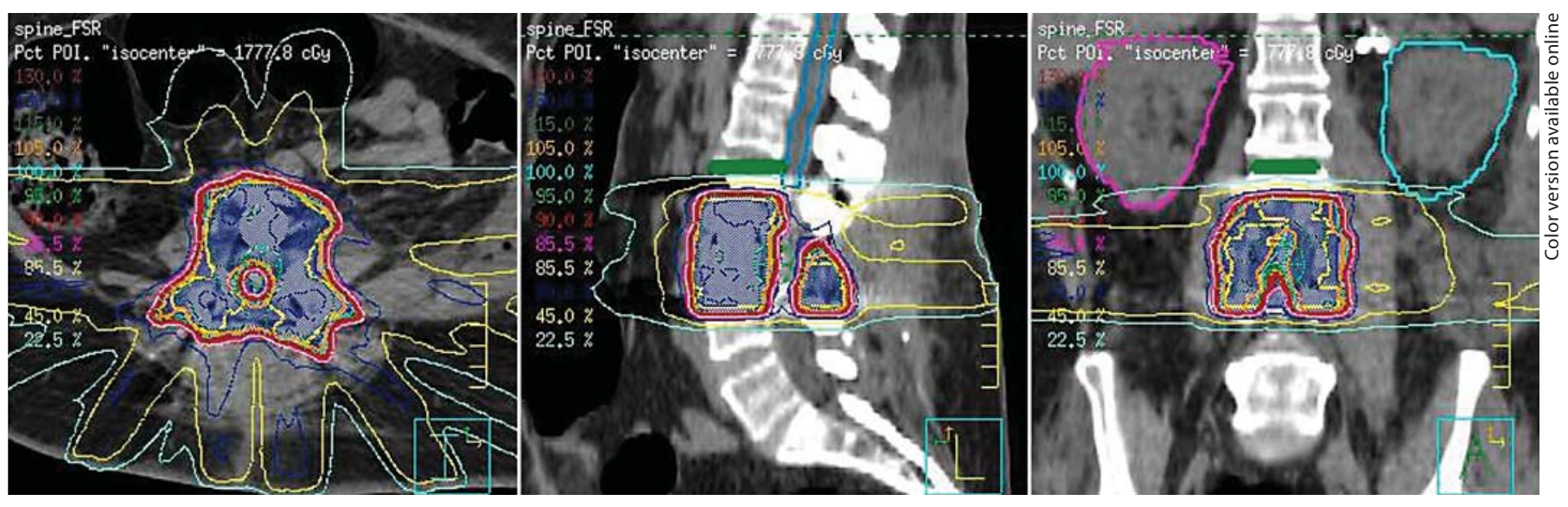

Fig. 1. Computed tomography images (axial, sagittal, coronal) with superimposed spinal stereotactic dosage plan of a metastatic adrenal adenocarcinoma lesion in the L3 vertebra.

pabilities for spinal lesions $[8,9]$. Initially, targeting was based on fiducial localization systems (often using implanted screws) for tumors in or around the mobile spine. Today, computer-aided guidance systems can recognize skeletal structures in the vicinity of the target area, thereby obviating the need for fiducials while allowing for adjustments during the treatment session to account for movement of the spine during SR.

The most commonly used SR machines include Synergy S (Elekta), Novalis (Brainlab) and Cyberknife. All use computed-tomography-based technology for treatment planning. Novalis and Cyberknife also use serial radiographs performed during SR treatment to identify any movement of the spine and change SR targeting accordingly. Synergy $S$ and Novalis utilize a mobile table to change targeting coordinates, while Cyberknife utilizes a mobile robotic arm. Data suggest that all systems have excellent accuracy, and studies suggest that targeting areas are probably close to $1 \mathrm{~mm}$ [9-12]. For example, Cyberknife was found to have a clinically relevant accuracy of $0.7 \pm 0.3 \mathrm{~mm}[12]$. Such systems minimize radiation exposure to the spinal cord and allow for the safe application of high doses of radiation to the target area [12].

Although SR for spinal lesions is in its infancy, there is a growing body of literature supporting its efficacy. The purpose of this review is to summarize the pertinent literature regarding the use of SR for lesions of the spine and spinal cord. Particular emphasis will be placed on large clinical series of both primary and secondary spine tumors.

\section{SR for Metastatic Spine Disease}

Metastatic spinal disease continues to be the cause of significant morbidity, as $40 \%$ of all cancer patients develop spinal metastases [13]. SR is currently well established as having a role in the treatment of intracranial metastatic disease $[5,6]$. The experience gained using SR for intracranial metastatic disease is now being translated to metastatic spine tumors (fig. 1). There are currently several large institutional series documenting the efficacy of SR for spinal metastatic disease [14-24] (table 1).

Gerszten et al. [14] reported the largest series of spine tumors treated with SR. A total of 393 patients were treated for 500 lesions involving the vertebral body. The vast majority were metastatic lesions. Of the 336 patients with pain as the primary indication for SR, $86 \%$ experienced long-term improvement in pain control. Pain control was more likely with certain tumor histology (breast, melanoma, renal and lung cancer). $88 \%$ of patients had radiographic evidence of local control. Interestingly, no patients had evidence of tumor progression at adjacent vertebral body levels. Nelson et al. [24] did not find adjacent level treatment failures in their series of 32 patients either. In contrast, Ryu et al. [25] reported that $4 \%$ of patients developed progression at adjacent vertebral levels in their series. When tumors do recur, it appears that they come back near the spinal cord. Chang et al. [21] found that the most common location of recurrence was the epidural space (47\%) followed by the pedicles and posterior elements (18\%). This suggests that the recurrence was along the portion of the tumor receiving the 
smallest dose or, perhaps, could have been a marginal miss [21].

Overall, the studies suggest that SR appears to provide excellent local control for metastatic spine cancer. All but 1 study report a greater than $80 \%$ local control rate. De Salles et al. [17] report the lowest rate of local control (56\%). However, in closely examining their series, $93 \%$ of patients were previously radiated, and $50 \%$ had prior surgical intervention for these lesions. In contrast, studies such as that by Degen et al. [22] reported 100\% local control in patients who had no prior radiation treatment. Also, Amdur et al. [20] reported in their prospective series of 21 patients with metastatic spine cancer that $95 \%$ of treated lesions were locally controlled after SR therapy. The high rate of local control may be partially explained by the short survival time of this cohort, as the median survival was only 8 months [20].

In terms of pain control, SR appears to have excellent efficacy in improving pain attributable to metastatic disease. A large proportion (43-97\%) of patients experienced improvement in back pain after SR. This data is comparable to that reported for patients receiving standard fractionated radiotherapy for spine metastases [26].

SR appears to also reverse neurological decline. Gerszten et al. [14] reported that patients experienced improvement in radiculopathies. However, the efficacy of SR in reversing preexisting neurological decline from cord compression is unclear. Many studies have excluded patients with metastatic spine tumors that lead to significant spinal cord compression. Milker-Zabel et al. [23] report that $42 \%$ of patients obtained improvement in neurological symptoms after SR. In contrast, Nelson et al. [24] report that none of the 7 patients with neurological deficits from cord compression improved after SR.

\section{Side Effects}

Overall morbidity that is directly attributable to SR is quite low. Decline in neurological function after SR is usually a manifestation of tumor progression rather than radiation toxicity. In the review by Benzil et al. [16] of 31 patients with SR, 2 patients developed radiculitis after SR. Both patients had biologically effective dose values greater than 60 Gy. Ryu et al. $[19,25]$ recently updated their institutional series of patients with metastatic spine cancer treated with SR. 177 patients were treated for 230 lesions using single-dose SR (8-18 Gy). Of the 86 patients who were alive after 1 year, only 1 patient experienced radiation-induced myelopathy $[19,25]$.

Stereotactic Radiosurgery for Spine Tumors
Vertebral compression fracture is another phenomenon that has occurred after SR $[18,21,25]$. Although they are thought to occur secondary to tumor progression, compression fractures have been documented after SR in patients without evidence of tumor progression [18]. While some believe that the treated vertebral body is structurally weaker, thereby predisposing the individual to a lower threshold of axial stress to cause a compression fracture, the mechanism of fracture has yet to be fully defined.

\section{SR for Benign Intradural Spine Tumors}

With the success of SR for metastatic spine tumors, clinicians have sought to expand the role of SR to primary spine tumors. Of particular interest are intradural tumors such as schwannomas, neurofibromas and meningiomas. The primary treatment option for the vast majority of intradural spine tumors continues to be surgical resection. The efficacy of surgical resection is well reported in the literature [27-31]. However, patients with significant comorbidities may not be able to tolerate surgical resection. Patients with multiple lesions throughout the craniospinal axis, as in the case of some patients with phakomatoses such as neurofibromatosis, may require extensive surgical resection with a significant risk of morbidity. In such patients, SR may be a useful treatment option. Patients who undergo incomplete surgical tumor resection may also potentially benefit from postoperative SR [32].

There are few large series in the literature regarding the outcome of intradural spinal tumors after SR (table 2). Gerszten et al. [34] report the largest series that includes 73 patients with benign spinal tumors (meningioma, schwannoma, neurofibroma). Local control was seen in $99 \%$ of tumors, and $70 \%$ of patients had improvement in pain control. Three patients developed SR-related neurological complications 5-13 months after treatment. All 3 lesions were located in the cervical spine [34].

Selch et al. [37] reported their series of 20 patients with benign nerve sheath tumors treated with SR. All patients had local control over a median follow-up of 18 months. Two patients experienced radiculopathy that resolved with conservative treatment [37].

Dodd et al. [33] reviewed 51 patients with 55 benign spinal tumors treated with radiosurgery. Local control was established in $98 \%$ of lesions. The authors note that only $39 \%$ of lesions decreased in size after SR and warn that SR may not be effective in reversing the mass effect produced by these tumors. Twelve patients in their series

Stereotact Funct Neurosurg 2010;88:315-321 
Table 1. Stereotactic radiosurgery for metastatic spine disease

\begin{tabular}{|c|c|c|c|c|c|c|c|c|}
\hline $\begin{array}{l}\text { Authors and } \\
\text { year }\end{array}$ & $\begin{array}{l}\text { Number } \\
\text { of patients/ } \\
\text { lesions }\end{array}$ & Age, years & $\begin{array}{l}\text { Intra/extra/ } \\
\text { metastatic } \\
\text { lesions }\end{array}$ & Method & $\begin{array}{l}\text { Mean follow-up } \\
\text { months }\end{array}$ & $\begin{array}{l}\text { Tumor } \\
\text { volume, } \mathrm{cm}^{3}\end{array}$ & \multicolumn{2}{|c|}{ Prior treatment, $\%$} \\
\hline Benzil et al. [16], 2004 & $31 / 35$ & $40-82($ mean 61$)$ & $4 / 5 / 26$ & Novalis & n.r. & n.r. & n.r. & n.r. \\
\hline Degen et al. [22], 2005 & $51 / 72$ & mean 53 & $0 / 14 / 58$ & Cyberknife & mean 12 & mean 115 & 0 & 53 \\
\hline Gerszten et al. [14], 2007 & $393 / 500$ & 18-85 (mean 56) & $0 / 0 / 500$ & Cyberknife & $3-53($ median 21$)$ & $0.2-264($ mean 46$)$ & 2 & 69 \\
\hline Jin et al. [15], 2007 & $196 / 270$ & n.r. & $0 / 0 / 270$ & Novalis & n.r. & n.r. & n.r. & n.r. \\
\hline Yamada et al. [18], 2008 & $93 / 103$ & 38-91 (median 62) & $0 / 0 / 103$ & n.r. & $2-45$ & n.r. & 0 & 0 \\
\hline
\end{tabular}

Target doses given in grays. Intra = Intradural primary tumor; extra = extradural primary tumor; n.r. = not recorded; PTV = planning target volume; $\mathrm{LC}=$ local control; OS = overall survival; $\mathrm{PI}=$ pain improvement; $\mathrm{RT}$ = radiation therapy; $\downarrow \mathrm{NU}=$ narcotic usage fell from 60 to $36 \%$ in 6 months.

Table 2. Stereotactic radiosurgery for benign intradural tumors

\begin{tabular}{lllllllcc}
\hline Authors and year & $\begin{array}{l}\text { Number } \\
\text { of patients/ } \\
\text { lesions }\end{array}$ & Age, years & $\begin{array}{l}\text { Intra/extra/ } \\
\text { metastatic } \\
\text { lesions }\end{array}$ & Method & $\begin{array}{l}\text { Mean follow-up } \\
\text { months }\end{array}$ & $\begin{array}{l}\text { Tumor } \\
\text { volume, } \mathrm{cm}^{3}\end{array}$ & $\begin{array}{l}\text { Prior treatment, \% } \\
\text { surgery }\end{array}$ & radiation \\
\hline Dodd et al. [33], 2005 & $51 / 55$ & $12-86$ (mean 46.5) & $55 / 0 / 0$ & Cyberknife & $6-73$ (median 25) & $0.14-24.6$ & 51 & 8 \\
\hline Gerszten et al. [34], 2008 & $73 / 73$ & $18-85$ (mean 44) & $73 / 0 / 0$ & Cyberknife & $8-71$ (median 37) & $0.3-93.4$ & 26 & 8 \\
\hline Ryu et al. [35], 2003 & $7 / 10$ & $19-61$ (mean 38) & $10 / 0 / 0$ & Cyberknife & $1-24$ (median 12) & $0.47-9.8$ & 57 & 29 \\
\hline Sahgal et al. [36], 2007 & $16 / 19$ & n.r. & $14 / 5 / 0$ & Cyberknife & $2-37$ (median 25) & $0.2-274.1$ & 26 & 5 \\
\hline Selch et al. [37], 2009 & $20 / 25$ & $17-78$ (median 61) & $25 / 0 / 0$ & Novalis & $12-58$ (median 18) & $0.5-13.7$ & 0 & 0 \\
\hline
\end{tabular}

Target doses given in grays. Intra = Intradural primary tumor; extra = extradural primary tumor; n.r. = not recorded; LC = local control; OS = overall survival; $\mathrm{PI}=$ pain improvement; $\mathrm{ME}=$ meningioma; $\mathrm{SC}=$ schwannoma; $\mathrm{NF}=$ neurofibroma; regression tumor size = percentage of treated lesions with radiographic evidence of decrease in tumor size.

presented with some degree of myelopathy secondary to cord compression from the tumor. Two of these patients required surgical intervention after SR because of persistent myelopathy [33]. The authors also note that patients with neurofibromas failed to achieve significant improvement in preoperative clinical symptoms after SR. This is in contrast to clinical outcomes of patients with meningiomas or schwannomas in their series. This observation mirrors the outcomes of spinal neurofibroma after surgical resection [31].

Sahgal et al. [36] reviewed their series of benign spinal tumors, 14 of which were primary intradural lesions. Of patients with tumors causing pain, $46 \%$ experienced improvement in pain after SR. Included in their series were 


\begin{tabular}{|c|c|c|c|c|c|c|c|}
\hline Target dose/isodose/fractions & Spinal cord dose limit & $\mathrm{LC}, \%$ & OS, $\%$ & PI, \% & $\begin{array}{l}\text { New } \\
\text { neurol. } \\
\text { deficit, \% }\end{array}$ & $\begin{array}{l}\text { Improved } \\
\text { neurol. } \\
\text { deficit, \% }\end{array}$ & $\begin{array}{l}\text { Major } \\
\text { non-neurol. } \\
\text { toxicity, \% }\end{array}$ \\
\hline $15 / 100 \%(95 \%$ to PTV) & $\begin{array}{l}\text { no prior RT: } 12 \text { Gy to } 0.1 \mathrm{~cm}^{3} \text {; } \\
\text { prior RT: } 5 \text { Gy to } 0.5 \mathrm{~cm}^{3}\end{array}$ & 95 & 25 & 43 & 0 & n.r. & 0 \\
\hline $5-50.4 / 85-90 \% / 1-28$ & $2.4-42.8$ Gy total dose & n.r. & 97 & 94 & 3 & n.r. & 6 \\
\hline $30 / 5$ fractions or $27 / 3$ fractions & $<10 \mathrm{~Gy}$ & 84 & 70 at 1 year & $\downarrow N U$ & n.r. & 0 & 5 \\
\hline $8-21 / 91 \%$ & n.r. & 56 & 71 & 50 & n.r. & n.r. & 0 \\
\hline $10-37.5 / 50-100 \% / 1-5$ & $2.2-27.1 \mathrm{~Gy}$ & 100 & 59 & 97 & 21 & n.r. & 0 \\
\hline $12.5-25 / 80 \%$ & $<8 \mathrm{~Gy}$ to mean $0.6 \mathrm{~cm}$ & 88 & n.r. & 86 & 0 & n.r. & 0 \\
\hline $10-18 / 90 \%$ & $<10 \mathrm{~Gy}$ to $10 \%$ volume & n.r. & n.r. & 85 & n.r. & n.r. & 0 \\
\hline $24-45 / 90 \%$ & $<20$ Gy point dose & 95 & 65 at 1 year & 81 & 5.5 & 42 & 0 \\
\hline 5.1-16/n.r./1-4 & varied & 87 & 66 at 1 year & 97 & 0 & 0 & 0 \\
\hline $8-18 / 90 \%$ & $<10 \mathrm{~Gy}$ to $10 \%$ volume & n.r. & 49 at 1 year & n.r. & 1 & n.r. & n.r. \\
\hline $18-24 / 100 \%$ & 12-14 Gy point dose & 90 & 36 at 3 years & n.r. & 0 & n.r. & 1 \\
\hline
\end{tabular}

\begin{tabular}{|c|c|c|c|c|c|c|c|c|}
\hline $\begin{array}{l}\text { Target dose/ } \\
\text { isodose/fractions }\end{array}$ & Spinal cord dose limit & LC, \% & OS & PI, \% & $\begin{array}{l}\text { Neurol. } \\
\text { deficit, \% }\end{array}$ & $\begin{array}{l}\text { Improved } \\
\text { neurol. deficit } \\
\%\end{array}$ & $\begin{array}{l}\text { Major } \\
\text { non-neurol. } \\
\text { toxicity }\end{array}$ & $\begin{array}{l}\text { Regression } \\
\text { tumor size } \\
\%\end{array}$ \\
\hline $16-30 / 80 \% / 1-5$ & $<10 \mathrm{~Gy}$ to $0.2 \mathrm{~cm}$ & 98 & n.r. & $70 \mathrm{ME}, 50 \mathrm{SC}, 0 \mathrm{NF}$ & 2 & n.r. & n.r. & 39 \\
\hline $15-25 / 80 \%$ & $8 \mathrm{~Gy}$ & 99 & n.r. & 73 & 5 & n.r. & n.r. & n.r. \\
\hline $18-25 / 68-82 \%$ & n.r. & 100 & n.r. & 43 & 0 & n.r. & 0 & 30 \\
\hline $10-30 / 80 \% / 1-5$ & $3.4-22.1 \mathrm{~Gy}$ to $0.1 \mathrm{~cm}$ & 83 & n.r. & 46 & 0 & n.r. & 0 & 30 \\
\hline $12-15 / 90-95 \%$ & $<10 \mathrm{~Gy}$ to $10 \%$ volume & 100 & n.r. & n.r. & 10 & 12 & 0 & 28 \\
\hline
\end{tabular}

4 patients with sacral chordoma, 3 of which were not treated previously. Of these 3 patients, there was no evidence of local progression (30-month median follow-up) [36].

Although the early results of SR for benign nerve sheath tumors are promising, a longer follow-up is necessary in order to properly evaluate the efficacy of this tech- nology. By nature, most of these tumors grow slowly, and there is no good study to demonstrate that the natural course or growth patterns of the tumors treated is altered by treatment. The cadence of relapse of acoustic neuromas may serve as a guide in this matter. For example, we have learned from our intracranial experience that the local progression rate after SR for acoustic neuromas in- 
creased over the first 3 years after treatment [38]. Patients with neurofibromatosis may be predisposed to late progression of nerve sheath tumors after SR [39].

\section{SR for Intramedullary Spinal Cord Tumors}

Radiation therapy is commonly utilized in the treatment of spinal cord tumors, particularly as an adjuvant therapy in conjunction with surgical resection. Current microsurgical techniques allow for safe resection of tumors [28]. However, there is a population where radiosurgery could provide a benefit. Postoperative radiation therapy may play a role in reducing tumor recurrence and improving long-term survival in spinal cord ependymomas and astrocytomas $[40,41]$. The role of radiation therapy, particularly SR, as a primary treatment modality is controversial. Ryu et al. [35] presented the largest series of intramedullary spinal tumors treated with SR. Seven hemangioblastomas and 3 ependymomas were treated. There was no evidence of tumor progression in any tumors, and 3 lesions decreased in size after SR [35].

\section{Conclusion}

The role of SR for tumors of the spine continues to be refined. Issues such as proper treatment dosage, spinal cord radiation tolerance, single-dose versus multi-dose SR continue to be investigated. However, despite the amazing accuracy and precision of our tools, we also have to acknowledge that the side effects can be devastating. Further refinements in hardware, software and techniques are still required.

The current literature provides support for SR as a primary treatment option for metastatic spine disease without evidence of spinal cord compression. SR may also play a role in the treatment of benign intradural tumors, particularly for patients who are poor candidates for definitive surgical resection. Evidence suggests that SR provides excellent local control and pain relief. Continued follow-up of these patients will help to elucidate the longterm outcomes of these patients.

\section{References}

1 Barnett GH, Linskey ME, Adler JR, Cozzens JW, Friedman WA, Heilbrun MP, Lunsford LD, Schulder M, Sloan AE: Stereotactic radiosurgery - an organized neurosurgerysanctioned definition. J Neurosurg 2007; 106:1-5.

2 Leksell L: The stereotaxic method and radiosurgery of the brain. Acta Chir Scand 1951; 102:316-319.

-3 Flickinger JC, Kondziolka D, Niranjan A, Lunsford LD: Results of acoustic neuroma radiosurgery: an analysis of 5 years' experience using current methods. J Neurosurg 2001;94:1-6.

4 Friedman WA, Bova FJ: The University of Florida radiosurgery system. Surg Neurol 1989;32:334-342.

$\checkmark 5$ Muacevic A, Wowra B, Siefert A, Tonn JC, Steiger HJ, Kreth FW: Microsurgery plus whole brain irradiation versus gamma knife surgery alone for treatment of single metastases to the brain: a randomized controlled multicentre phase III trial. J Neurooncol 2008;87:299-307.

6 Smith ML, Lee JY: Stereotactic radiosurgery in the management of brain metastasis. Neurosurg Focus 2007;22:E5.

-7 Hamilton AJ, Lulu BA, Fosmire H, Gossett L: Linac-based spinal stereotactic radiosurgery. Stereotact Funct Neurosurg 1996;66: $1-9$.
8 Adler JR Jr, Murphy MJ, Chang SD, Hancock SL: Image-guided robotic radiosurgery. Neurosurgery 1999;44:1299-1306, discussion 1306-1297.

-9 Chang SD, Main W, Martin DP, Gibbs IC, Heilbrun MP: An analysis of the accuracy of the Cyberknife: a robotic frameless stereotactic radiosurgical system. Neurosurgery 2003;52:140-146, discussion 146-147.

10 Kim S, Jin H, Yang H, Amdur RJ: A study on target positioning error and its impact on dose variation in image-guided stereotactic body radiotherapy for the spine. Int J Radiat Oncol Biol Phys 2009;73:1574-1579.

11 Yan H, Yin FF, Kim JH: A phantom study on the positioning accuracy of the Novalis body system. Med Phys 2003;30:3052-3060.

12 Yu C, Main W, Taylor D, Kuduvalli G, Apuzzo ML, Adler JR Jr: An anthropomorphic phantom study of the accuracy of Cyberknife spinal radiosurgery. Neurosurgery 2004;55: 1138-1149.

13 Klimo P Jr, Schmidt MH: Surgical management of spinal metastases. Oncologist 2004; 9:188-196.

14 Gerszten PC, Burton SA, Ozhasoglu C, Welch WC: Radiosurgery for spinal metastases: clinical experience in 500 cases from a single institution. Spine (Phila Pa 1976) 2007; 32:193-199.
15 Jin JY, Chen Q, Jin R, Rock J, Anderson J, Li S, Movsas B, Ryu S: Technical and clinical experience with spine radiosurgery: a new technology for management of localized spine metastases. Technol Cancer Res Treat 2007;6:127-133.

-16 Benzil DL, Saboori M, Mogilner AY, Rocchio R, Moorthy CR: Safety and efficacy of stereotactic radiosurgery for tumors of the spine. J Neurosurg 2004;101(suppl 3):413-418.

17 De Salles AA, Pedroso AG, Medin P, Agazaryan N, Solberg T, Cabatan-Awang C, Espinosa DM, Ford J, Selch MT: Spinal lesions treated with Novalis shaped beam intensitymodulated radiosurgery and stereotactic radiotherapy. J Neurosurg 2004;101(suppl 3):435-440.

18 Yamada Y, Bilsky MH, Lovelock DM, Venkatraman ES, Toner S, Johnson J, Zatcky J, Zelefsky MJ, Fuks Z: High-dose, single-fraction image-guided intensity-modulated radiotherapy for metastatic spinal lesions. Int $J$ Radiat Oncol Biol Phys 2008;71:484-490.

19 Ryu S, Jin JY, Jin R, Rock J, Ajlouni M, Movsas B, Rosenblum M, Kim JH: Partial volume tolerance of the spinal cord and complications of single-dose radiosurgery. Cancer 2007;109:628-636. 
20 Amdur RJ, Bennett J, Olivier K, Wallace A, Morris CG, Liu C, Mendenhall WM: A prospective, phase II study demonstrating the potential value and limitation of radiosurgery for spine metastases. Am J Clin Oncol 2009, E-pub ahead of print.

-21 Chang EL, Shiu AS, Mendel E, Mathews LA, Mahajan A, Allen PK, Weinberg JS, Brown BW, Wang XS, Woo SY, Cleeland C, Maor $\mathrm{MH}$, Rhines LD: Phase I/II study of stereotactic body radiotherapy for spinal metastasis and its pattern of failure. J Neurosurg Spine 2007;7:151-160.

-22 Degen JW, Gagnon GJ, Voyadzis JM, McRae DA, Lunsden M, Dieterich S, Molzahn I, Henderson FC: Cyberknife stereotactic radiosurgical treatment of spinal tumors for pain control and quality of life. J Neurosurg Spine 2005;2:540-549.

-23 Milker-Zabel S, Zabel A, Thilmann C, Schlegel W, Wannenmacher M, Debus J: Clinical results of retreatment of vertebral bone metastases by stereotactic conformal radiotherapy and intensity-modulated radiotherapy. Int J Radiat Oncol Biol Phys 2003;55:162167.

-24 Nelson JW, Yoo DS, Sampson JH, Isaacs RE, Larrier NA, Marks LB, Yin FF, Wu QJ, Wang Z, Kirkpatrick JP: Stereotactic body radiotherapy for lesions of the spine and paraspinal regions. Int J Radiat Oncol Biol Phys 2009;73:1369-1375.

25 Ryu S, Rock J, Rosenblum M, Kim JH: Patterns of failure after single-dose radiosurgery for spinal metastasis. J Neurosurg 2004; 101(suppl 3):402-405.
26 Rose CM, Kagan AR: The final report of the expert panel for the radiation oncology bone metastasis work group of the American College of Radiology. Int J Radiat Oncol Biol Phys 1998;40:1117-1124.

27 Conti P, Pansini G, Mouchaty H, Capuano C, Conti R: Spinal neurinomas: retrospective analysis and long-term outcome of 179 consecutively operated cases and review of the literature. Surg Neurol 2004;61:34-43, discussion 44.

28 Gezen F, Kahraman S, Canakci Z, Beduk A Review of 36 cases of spinal cord meningioma. Spine (Phila Pa 1976) 2000;25:727-731.

29 Klekamp J, Samii M: Surgery of spinal nerve sheath tumors with special reference to neurofibromatosis. Neurosurgery 1998;42:279289, discussion 289-290.

-30 Parsa AT, Lee J, Parney IF, Weinstein P, McCormick PC, Ames C: Spinal cord and intradural-extraparenchymal spinal tumors: current best care practices and strategies. J Neurooncol 2004;69:291-318.

- 31 Seppala MT, Haltia MJ, Sankila RJ, Jaaskelainen JE, Heiskanen O: Long-term outcome after removal of spinal neurofibroma. J Neurosurg 1995;82:572-577.

32 Rock JP, Ryu S, Shukairy MS, Yin FF, Sharif A, Schreiber F, Abdulhak M, Kim JH, Rosenblum ML: Postoperative radiosurgery for malignant spinal tumors. Neurosurgery 2006;58:891-898, discussion 891-898.

33 Dodd RL, Ryu MR, Kamnerdsupaphon P, Gibbs IC, Chang SD Jr, Adler JR Jr: Cyberknife radiosurgery for benign intradural extramedullary spinal tumors. Neurosurgery 2006;58:674-685, discussion 674-685.
34 Gerszten PC, Burton SA, Ozhasoglu C, McCue KJ, Quinn AE: Radiosurgery for benign intradural spinal tumors. Neurosurgery 2008;62:887-895, discussion 895-896.

-35 Ryu SI, Kim DH, Chang SD: Stereotactic radiosurgery for hemangiomas and ependymomas of the spinal cord. Neurosurg Focus 2003; 15:E10.

- 36 Sahgal A, Chou D, Ames C, Ma L, Lamborn K, Huang K, Chuang C, Aiken A, Petti P, Weinstein $\mathrm{P}$, Larson D: Image-guided robotic stereotactic body radiotherapy for benign spinal tumors: the University of California San Francisco preliminary experience. Technol Cancer Res Treat 2007;6:595-604.

37 Selch MT, Lin K, Agazaryan N, Tenn S, Gorgulho A, Demarco JJ, De Salles AA: Initial clinical experience with image-guided linear accelerator-based spinal radiosurgery for treatment of benign nerve sheath tumors. Surg Neurol 2009;72:668-674, discussion 674-675.

38 Kondziolka D, Lunsford LD, McLaughlin MR, Flickinger JC: Long-term outcomes after radiosurgery for acoustic neuromas. $\mathrm{N}$ Engl J Med 1998;339:1426-1433.

- 39 Ito K, Shin M, Matsuzaki M, Sugasawa K, Sasaki T: Risk factors for neurological complications after acoustic neurinoma radiosurgery: refinement from further experiences. Int J Radiat Oncol Biol Phys 2000;48:75-80.

$\checkmark 40$ Isaacson SR: Radiation therapy and the management of intramedullary spinal cord tumors. J Neurooncol 2000;47:231-238

-41 Kopelson G, Linggood RM, Kleinman GM, Doucette J, Wang CC: Management of intramedullary spinal cord tumors. Radiology 1980;135:473-479. 